\title{
Blending Municipal Solid Waste with Corn Stover for Sugar Production Using Ionic Liquid Process
}

Ning Sun, ${ }^{\mathrm{a}}$ Feng Xu, ${ }^{\mathrm{a}, \mathrm{b}}$ Noppadon Sathitsuksanoh, ${ }^{\mathrm{a}}$ Vicki S Thompson, ${ }^{\mathrm{c}}$ Kara Cafferty, Chenlin Li, ${ }^{\mathrm{e}}$ Deepti Tanjore, ${ }^{\mathrm{e}}$ Akash Narani, ${ }^{\mathrm{e}}$ Todd R. Pray, ${ }^{\mathrm{e}}$ Blake A. Simmons ${ }^{\mathrm{a}, \mathrm{b}}$ and Seema Singh* ${ }^{\mathrm{a}, \mathrm{b}}$

7

$8 \quad{ }^{a}$ Deconstruction Division, Joint BioEnergy Institute, Lawrence Berkeley National Laboratory, 9 Berkeley, CA, USA

$10{ }^{\mathrm{b}}$ Biological and Materials Sciences Center, Sandia National Laboratories, Livermore, CA, 11 USA

$12{ }^{\mathrm{c}}$ Idaho National Laboratory, Biological and Chemical Processing Department, Idaho Falls, ID, 13 USA

14 ddaho National Laboratory, Environmental Engineering and Technology, Idaho Falls, ID, 15 USA

$16{ }^{\mathrm{e}}$ Advanced Biofuel Process Demonstration Unit, Lawrence Berkeley National Laboratory, 17 Berkeley, CA, USA 


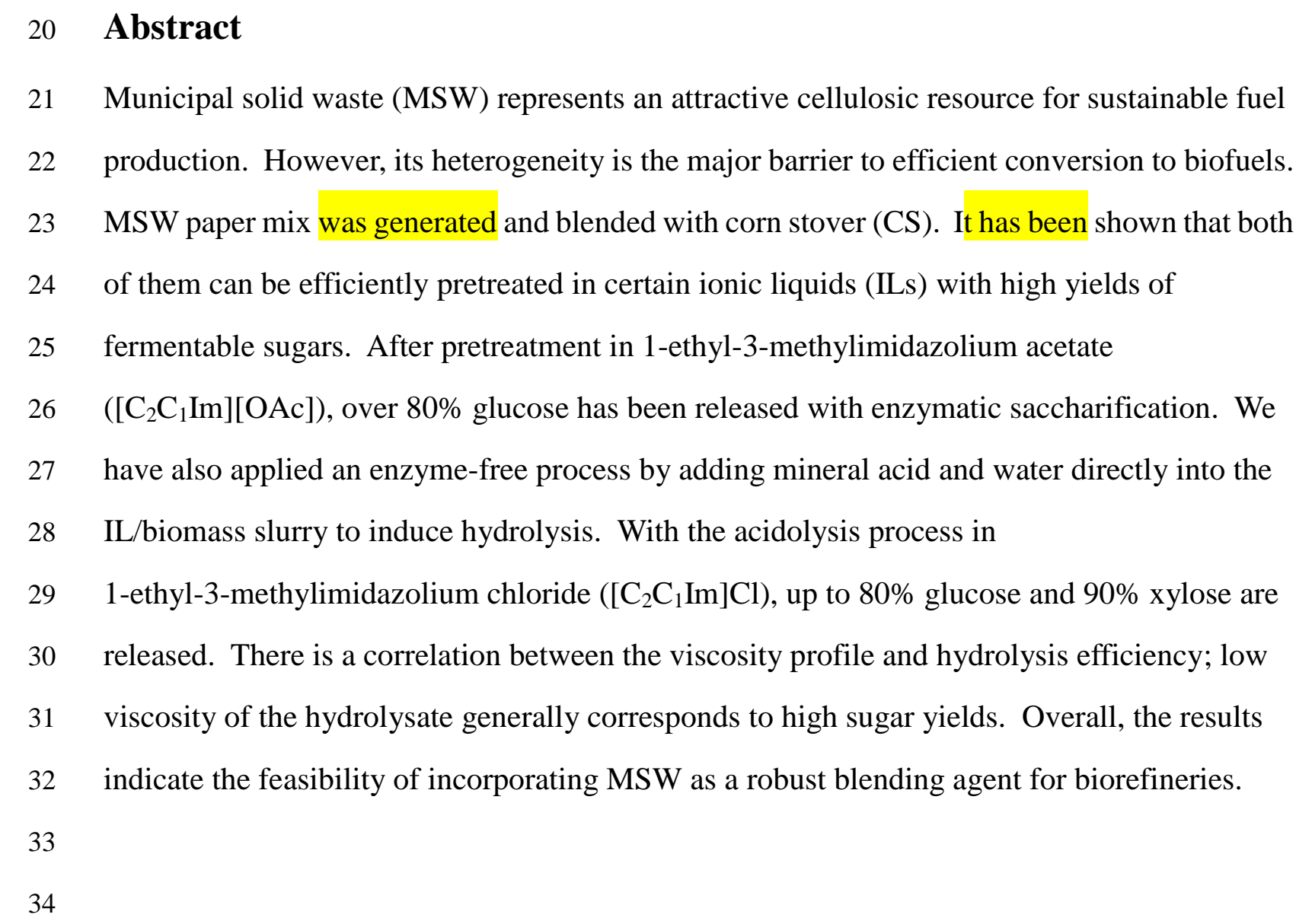

35 Keywords: Mixed feedstocks, biomass pretreatment, municipal solid waste, paper mix, ionic 36 liquid, acidolysis. 


\section{Introduction}

Renewable energy technologies are being developed as new sources of fuels and power to meet our current and future energy needs. Lignocellulosic biomass is an important renewable source for production of biofuels and bio-products. Significant attention has been historically given to agriculturally-derived feedstocks; however a diverse range of wastes, including municipal solid wastes (MSW) also have potential to serve as feedstocks for the production of advanced biofuels due to its abundance and low cost (The Biomass Research and Development Board Report, 2008; Williams, 2007). Compared with the seasonal availability of agricultural wastes, MSW has the advantage of year-round availability, an established collection infrastructure and potential availability at negative cost (Williams, 2007). An efficient use of MSW would not only benefit biofuel industry but also reduce landfill disposal (Williams, 2007). Recent reports projected that an estimated 44.5 million dry tons of MSW will be available in 2022 in the United States, among which paper mix is one of the major components, representing about 30\% of total MSW (Environmental Protection-Agency Report, 2010).

Biomass feedstock costs remain a large contributor to biofuel production costs

(Klein-Marcuschamer et al., 2010). The costs could be reduced by blending more expensive high quality feedstocks with lower cost, lower quality feedstocks such that the overall quality still meets specifications required by the biorefinery and the final costs are reduced (Thompson, 2014).

Among the various options of biomass pretreatment strategies, ionic liquid (IL) pretreatment with imidazolium-based ILs has been proven to be one of the most effective ways for biomass processing, primarily due to the efficient solubilization and perturbation of the major components of the plant cell wall, which makes the biomass structure amenable for downstream processing (Li et al., 2010; Sun et al., 2013; Xu et al., 2012). The conversion to sugars can be realized biologically by using commercial enzyme mixtures, or chemically by using mineral acid as a catalyst (Binder \& Raines, 2010; Li et al., 2010). Enzymatic hydrolysis is frequently used for polysaccharide hydrolysis to monosaccharides after biomass pretreatment. However, the saccharification process takes as long as 2 to 3 days, and enzyme cost is the second highest contributor to material costs of the biofuel conversion process after 
those associated with the feedstock input itself (Klein-Marcuschamer et al., 2010). Acidolysis in certain ILs has been reported as an enzyme-free process for biomass conversion (Binder \& Raines, 2010). By using a direct injection of acid and water after IL pretreatment, both pentose and hexose are released from polysaccharides within 2-3 hours. The significant reduction of processing time would be a great benefit for biorefineries due to the increased productivity and significant cost reduction. In addition, there is no need for ionic liquid separation or solid-liquid separation before acidolysis. Our previous study showed up to $83 \%$ of glucose and 99\% of xylose liberation from switchgrass with the imidazolium chloride IL pretreatment followed by acidolysis (Sun et al., 2013). To date, there is no known published report on evaluating the performance of IL pretreatment for the processing of MSW and MSW blends. In this study, both enzymatic hydrolysis and dilute acid hydrolysis were evaluated in terms of sugar production from feedstock blends.

\section{Materials and Methods}

\subsection{Raw materials}

The paper waste materials, consisting of 15\% glossy paper, $25 \%$ non-glossy paper, $31 \%$ non-glossy cardboard, and $28 \%$ glossy cardboard, were collected over the course of two weeks from one of the Idaho National Laboratory (INL) buildings and utilized to represent the MSW material in this study. The MSW paper material was shredded through a conventional office shredder and the cardboard material was cut into pieces with scissors. Each paper type was ground to $2 \mathrm{~mm}$ using a Thomas Scientific Model 4 Laboratory Wiley Mill (Thomas Scientific, Swedesboro, NJ). The corn stover was grown near Emmitsburgh (IA, USA) and was harvested in September 2010. Harvested corn stover was ground using a Vermeer BG480 grinder (Vermeer, IA, USA) designed for processing up to $4 \mathrm{x} 4 \mathrm{ft}$ bales. A 1 -inch screen was used for these grinds. The MSW paper materials were then mixed with previously ground corn stover (CS) in different ratios. The $\left.\mathrm{IL}_{[} \mathrm{C}_{2} \mathrm{C}_{1} \mathrm{Im}\right][\mathrm{OAc}]$ (>95\% purity) was purchased from BASF (Ludwigshafen, Germany). $\left[\mathrm{C}_{2} \mathrm{C}_{1} \mathrm{Im}\right] \mathrm{Cl}$ (>97\% purity) and $6 \mathrm{~N}$ hydrochloric acid were purchased from Sigma-Aldrich. 


\subsection{Feedstock cost determination}

DOE has set a cost target of $\$ 80 /$ ton for feedstock delivered to the biorefinery. This target was developed to address barriers involved with commercializing logistics systems to be cost competitive with petroleum fuels. INL has developed several feedstock logistics models that calculate the costs associated with harvest and collection, storage, preprocessing, handling and transportation of feedstocks. The Biomass Logistics Model (BLM) simulating the flow of biomass throughout the entire supply chain and accounting for cost as different unit operations are applied. This model is used to evaluate supply chain designs in order to meet DOE targets. The BLM is an integrated model whose analytic engine is developed in the system dynamic software package Powersim ${ }^{\mathrm{TM}}$. Additionally, the Least Cost Formulation Model (LCF) combines grower payment/access cost from the Billion Ton Update (BT2) with logistics costs from the BLM and feedstock quality characteristics from the Biomass Resource Library to estimate the total cost of feedstock to the throat of the biorefinery. The LCF model is developed in a simulation software package AnyLogic ${ }^{\mathrm{TM}}$. The concept behind LCF is similar to the animal feed industry where the goal is to provide the least expensive combination of feed constituents (soybean meal, corn meal, etc.) while meeting nutrient requirements for desired animal growth. For example, the University of Georgia Athen's Windows User-Friendly Feed Formulation for Poultry and Swine (WUFFDA) model generates least cost animal feed formulations for desired feed ingredients. Where the feed industry pursues desired yield (animal weight gain) the biofuel industry's targets fuel production, both trying to minimize cost while maintaining performance. The LCF joins output of models and databases (BLM, BT2, Biomass Resource Library) to generate the delivered costs of feedstock formulations to direct research to help meet the $\$ 80 /$ ton target.

\subsection{Pretreatment in $\left[\mathrm{C}_{2} \mathrm{C}_{1} \mathrm{Im}\right][\mathrm{OAc}]$ followed by enzymatic saccharification}

Pretreatment A 10\% (w/w) biomass solution was prepared by combining $2 \mathrm{~g}$ of MSW or MSW/CS blends with $18 \mathrm{~g}$ of $\left[\mathrm{C}_{2} \mathrm{C}_{1} \mathrm{Im}\right][\mathrm{OAc}]$ in a $50 \mathrm{~mL}$ Globe reactor (Syrris, UK). The reactor was heated to the desired temperature $\left(140^{\circ} \mathrm{C}\right.$, ramp time: 40 minutes $)$ and stirred at $300 \mathrm{rpm}$ with a Teflon overhead stirrer. Following pretreatment, $60 \mathrm{~mL}$ of $95 \%$ ethanol was slowly added to the biomass/IL slurry with continued stirring. The mixture was transferred in to $50 \mathrm{~mL}$ Falcon tubes and centrifuged at high speed $(14,000 \mathrm{rpm})$ to separate the solids. 
Additional solids were collected from the supernatant by nylon mesh filtration (1 micron pore size), and the combined pretreated biomass was washed two additional times with $60 \mathrm{~mL}$ DI water to remove any residual IL. The solids were again filtered through 1 micron nylon mesh and stored at $4{ }^{\circ} \mathrm{C}$ for analysis.

Enzymatic saccharification Enzymatic saccharification of pretreated and untreated biomass was carried out at $50^{\circ} \mathrm{C}$ and $\mathrm{pH} 5.5$ at $150 \mathrm{rpm}$ in a rotary incubator (Enviro-Genie, Scientific Industries, Inc.) using commercial enzyme mixtures, Cellic ${ }^{\circledR}$ CTec2 (batch number VCN10001) and HTec2 (batch number VHN00001), obtained as a gift from Novozymes. The protein content of enzymes was determined by bicinchoninic acid (BCA) assay with a Pierce BCA Protein Assay Kit (Thermo Scientific) using BSA as protein standard. CTec2 has a protein content of $186.6 \pm 2.0 \mathrm{mg} / \mathrm{mL}$, and protein content of HTec2 is $180.1 \pm 1.8 \mathrm{mg} / \mathrm{mL}$ protein (Socha et al., 2014). All reactions were conducted at 10\% biomass loading by placing $500 \mathrm{mg}$ of biomass (dry weight) in a $25 \mathrm{~mL}$ centrifuge tube. The $\mathrm{pH}$ of the mixture was adjusted with $50 \mathrm{mM}$ sodium citrate buffer ( $\mathrm{pH} 4.8)$ supplemented with $0.02 \%(\mathrm{v} / \mathrm{v}) \mathrm{NaN}_{3}$ to prevent microbial contamination. The total volume of $5 \mathrm{~mL}$ included a total protein content of $20 \mathrm{mg}$ protein/g glucan as determined by compositional analysis, with the volumetric ratio of $\mathrm{CTec} 2: \mathrm{HTec} 2=9: 1$. Reactions were monitored by centrifuging $50 \mu \mathrm{L}$ aliquots of supernatant (5 min, $10,000 \mathrm{x} \mathrm{g}$ ) in spin-filter centrifugal tubes with $0.45 \mu \mathrm{m}$ nylon filter at specific time intervals and measuring monomeric sugar concentrations by HPLC.

\subsection{Acidolysis in $\left[\mathrm{C}_{2} \mathrm{C}_{1} \mathrm{Im}\right] \mathrm{Cl}$}

Biomass solutions were prepared by combining $3 \mathrm{~g}$ of biomass with $17 \mathrm{~g}\left[\mathrm{C}_{2} \mathrm{C}_{1} \mathrm{Im}\right] \mathrm{Cl}$ in a 100 $\mathrm{mL}$ Globe reactor (Syrris, UK). The mixtures were programmed to be heated to different temperatures $\left(120^{\circ} \mathrm{C}, 140^{\circ} \mathrm{C}\right.$, and $160^{\circ} \mathrm{C}$; ramp time: $30-40$ minutes) and hold for $2 \mathrm{~h}$. The solutions were then cooled down to the acidolysis temperature of $105^{\circ} \mathrm{C}$ and acidolysis started after 15 min equilibration time. Acidolysis was performed following a procedure described previously (Sun et al., 2013). In summary, $2.07 \mathrm{~mL} 4 \mathrm{M} \mathrm{HCl}$ was added to the biomass- $\left[\mathrm{C}_{2} \mathrm{C}_{1} \operatorname{Im}\right] \mathrm{Cl}$ solution ( $\left.\mathrm{t}=0\right)$ and with DI water added to give a $\mathrm{H}_{2} \mathrm{O}$ concentration of $5 \%$ $(w / w)$ of the total weight. More water $(3.175 \mathrm{~mL})$ was added at $10 \mathrm{~min}$ to get the targeted water concentration of $20 \%$. Water was injected into the mixture starting from $15 \mathrm{~min}$ at the rate of $227.5 \mathrm{uL} / \mathrm{min}$ for $45 \mathrm{~min}$. Acidolysis was continued for a total of $2.5 \mathrm{~h}$ and stopped by 
cooling down the reactor to room temperature. Time points were taken every 30 min during acidolysis to monitor sugar yield by HPLC.

\subsection{Analysis and characterization methods}

Moisture analysis Moisture content of pretreated biomass was quantified using a moisture content analyzer (Mettler Toledo, Model HB43-S Halogen) by heating to $105^{\circ} \mathrm{C}$ and monitoring the mass until it remained constant.

Biomass composition and sugar hydrolysate analysis Compositional analysis before and after pretreatment was determined using NREL acidolysis protocols (LAP) LAP-002 and LAP-005 (Sluiter, 2004). Briefly, $200 \mathrm{mg}$ of biomass and $2 \mathrm{~mL} 72 \% \mathrm{H}_{2} \mathrm{SO}_{4}$ were incubated at $30{ }^{\circ} \mathrm{C}$ while shaking at $300 \mathrm{rpm}$ for $1 \mathrm{~h}$. The solution was diluted to $4 \% \mathrm{H}_{2} \mathrm{SO}_{4}$ with $56 \mathrm{~mL}$ of DI water and autoclaved for $1 \mathrm{~h}$ at $121^{\circ} \mathrm{C}$. The reaction was quenched by placing the samples into an ice bath before removing the biomass by filtration. Carbohydrate concentrations were determined from the filtrate by Agilent HPLC 1200 Series equipped with a Bio-Rad Aminex HPX-87H column and a Refractive Index detector, and acid insoluble lignin was quantified gravimetrically from the solid biomass after heating overnight at $105^{\circ} \mathrm{C}$.

Rheology analysis A stress controlled Malvern Kinexus Rheometer (Worcestershire, UK) with $40 \mathrm{~mm}$ diameter parallel plate geometry was used to measure the viscosity and phase angle of all materials. The materials were refrigerated immediately after treatments and thawed to room temperature prior to performing viscosity studies. All viscosity measurements were conducted at $25^{\circ} \mathrm{C}$ at varying shear rate from 0 to $150 \mathrm{~s}^{-1}$. Gap heights of 2 to $5 \mathrm{~mm}$ were set for acidolysis and pretreated solids, respectively, to engage the materials between the plates for accurate measurements. Care was taken to avoid air bubbles trapped in the sample. Also, bulging of the sample on the edges of the plates was ensured to avoid end effects. Clear drop in viscosity was observed with increasing shear rate in all samples. Accordingly, the tested portion of the samples were discarded and not re-used for further measurements due to lack of confidence in material integrity.

\section{Results and discussions}

Least Cost Formulation for CS/MSW blends Figure 1a shows predicted delivered feedstock 
costs for corn stover from the LCF model assuming 2017 state of technology with projected supply chain costs and resource availability(INL/EXT-13-30342, 2013)(INL/EXT-13-30342, 2013)(INL/EXT-13-30342, 2013). Areas shown in light blue are approximately $\$ 80 /$ ton, capable of meeting DOE targets, but only a few locations exists, all of which are in high productivity corn growing areas. To sustain a national scale biorefining industry, more locations need to be capable of meeting the DOE biomass cost target. INL has been exploring the concept of blending lower cost feedstock to reduce overall feedstock costs while maintaining quality specifications required by the biorefinery. The LCF model integrates individual feedstock logistics costs and grower payment/access fees from models developed previously (BLM, BT2) to determine the formulated cost for a blend in a given region of the U.S. Figures $1 \mathrm{~b}$ and $1 \mathrm{c}$ show the delivered feedstock costs for CS:MSW blends of 80:20, and 50:50. For the other blend ratios (90:10, 70:30, and 60:40) the costs are shown in Figure 1S. As can be seen, as the amount of MSW increases, more areas have feedstock available at $\$ 80 /$ ton or less including areas outside of the traditional Midwest Corn Belt. The high availability of MSW near large cities in the Midwest provides states like Illinois, Indiana, Ohio and Michigan with sufficient biomass resources to support biorefinery development. The other key aspect of blending is whether or not the blend meets quality specifications needed for efficient conversion. Using the CS and MSW compositions in Table 1, the various blends of corn stover and MSW would yield ash and sugar specifications shown in Table 2. Since the sugar composition (glucan + xylan) of the corn stover and MSW are very similar, the sugar compositions of the blends do not vary much. However, the ash changes from 3.8\% for the $90: 10$ blend to $7.0 \%$ for the 50:50 blend. Although all of the blends meet the cost target, they may not all meet the required biorefinery specification target and those factors need to be considered as well. For example, if a biorefinery ash target was set at 5\%, then only the 90:10 and 80:20 blends should be considered. If that target could be relaxed, then more areas of the U.S. would have sufficient biomass.

$\left[\mathrm{C}_{2} \mathbf{C}_{1} \mathrm{Im}\right][\mathbf{O A c}]$ pretreatment Reports using $\left[\mathrm{C}_{2} \mathrm{C}_{1} \mathrm{Im}\right][\mathrm{OAc}]$ to pretreat biomass have typically used temperatures between $120-160^{\circ} \mathrm{C}$ and time intervals of $1-3 \mathrm{~h}$ to achieve high sugar yields. (Li et al., 2010; Sun et al., 2014) In the present study we chose $140{ }^{\circ} \mathrm{C}$ for $3 \mathrm{~h}$ to 
get an initial evaluation of the convertibility of MSW or MSW blend (CS/MSW=1:1). Table 1 shows compositional analysis before and after IL pretreatment. Three of the major plant cell wall components, glucan, xylan, and acid-insoluble lignin, were monitored before and after pretreatment. Solid recovery refers to the mass percentage of biomass (dry weight) recovered from the original biomass load. After washing, $72 \%$ of the corn stover, $77 \%$ of the CS/MSW (1:1) blend and $93 \%$ of the MSW was recovered. We hypothesize that the higher recovery of MSW is due to the high content of glucan in MSW and $\left[\mathrm{C}_{2} \mathrm{C}_{1} \mathrm{Im}\right][\mathrm{OAc}]$ pretreatment mainly removes lignin and hemicelluloses (Sun et al., 2014). After pretreatment, the glucan loading increased with decreased lignin content for both CS and MSW/CS (1:1). After pretreatment of MSW, the compositions of the major components remain similar compared to the raw starting material. As shown in Figure 2, a significant amount of lignin (78\%) initially present in the CS has been removed after pretreatment. However, only 9.2\% lignin was removed from MSW. We attribute this difference to the nature of the lignin in these two feedstocks. For MSW, the paper mix has already gone through a pulping process that removed most of the lignin from the biomass, as verified by the compositional analysis of the starting material. The remaining lignin structure is thus expected to be more recalcitrant compared to the intact lignin in CS, thus more difficult to be removed.

To compare glucan digestibility, enzymatic hydrolysis of untreated and pretreated biomass was carried out using commercial enzyme cocktails, Novozymes Cellic® CTec2 and HTec2. For each sample, enzyme loadings were normalized to glucan content as determined by compositional analysis. Pretreated samples were used without drying, and solid loading (as 10\% dry weight in the hydrolysis slurry) was calculated based on moisture content determined for each sample. Glucan and xylan yields after $72 \mathrm{~h}$ are plotted in Figure 3. After IL pretreatment, significantly faster saccharification rates and higher sugar yields were achieved for all the three feedstocks. All glucose yields (calculated based on the glucan present in pretreated biomass) were above $90 \%$ with final glucose concentrations reaching $50 \mathrm{~g} / \mathrm{L}$. Most glucan to glucose conversion was complete after $24 \mathrm{~h}$ of enzymatic hydrolysis. Xylan conversion was also significantly improved with relatively lower yields compared to glucose, primarily due to hemicellulose solubilization during pretreatmnt. The mass balance of the 
pretreatment/hydrolysis process is shown in Figure 3. After pretreatment 78.1\% lignin, 8.9\% xylan and $11.7 \%$ glucan was removed from CS; $5.9 \%$ lignin, $0.9 \%$ xylan and $15.2 \%$ glucan was removed from MSW; and 58.8\% lignin, 27.6\% xylan and 7.1\% glucan was removed from MSW/CS (1:1) blend. More xylan removal and less glucan removal were unexpected with MSW/CS blend compared to the two biomass feedstocks individually, which may be due to the rheology change after blending with CS (discussed in later section). Overall, $82.5 \%$ glucose yield and $43.4 \%$ xylose yield were obtained for CS; $81.9 \%$ glucose yield and $75.2 \%$ xylose yield were obtained for MSW; and $84.0 \%$ glucose yield and $40.0 \%$ xylose yield were obtained for MSW/CS blends (yields calculated based on the glucan or xylan in original biomass).

These results show that IL pretreatment is efficient for MSW as well as MSW/CS blends, and the pretreated materials are readily to be converted to sugar using commercial cellulolytic enzyme. Figure $2 \mathrm{~S}$ showed the powder X-ray diffractograms

Acidolysis in $\left[\mathbf{C}_{2} \mathbf{C}_{1} \mathbf{I m}\right] \mathbf{C l}$ To test the feasibility of chemical conversion of MSW blends, one-pot sugar conversion using mineral acid $(\mathrm{HCl})$ has been carried out in the $\mathrm{IL}\left[\mathrm{C}_{2} \mathrm{C}_{1} \mathrm{Im}\right] \mathrm{Cl}$. $[\mathrm{C} 2 \mathrm{C} 1 \mathrm{Im}] \mathrm{Cl}$ instead of $[\mathrm{C} 2 \mathrm{C} 1 \mathrm{Im}][\mathrm{OAc}]$ was used for acidolysis process since there is no anion exchange with the acid $(\mathrm{HCl})$ used in the hydrolysis step. Different pretreatment temperatures and blending ratios were attempted to test the effect of conversion. The results are shown in Figure 4 and Table 1S. The sugar yields obtained after pretreatment and hydrolysis were calculated using Eq. 1:

$$
\text { Yield } \%=\frac{C_{\text {sup }} \times M_{\text {sup }}}{W \times C \times f} \times 100 \%
$$

where, $C_{\text {sup }}$ is the sugar concentration of the supernatant (w/w), $M_{\text {sup }}$ is the mass of the supernatant, $W$ is the weight of the biomass, $C$ is the percentage of glucan or xylan contained in the biomass, and $f$ is the factor to convert glucan or xylan to glucose or xylose (1.11 for glucan and 1.136 for xylan). After pretreatment at $120^{\circ} \mathrm{C}$, neither MSW nor corn stover dissolved well in $\left[\mathrm{C}_{2} \mathrm{C}_{1} \mathrm{Im}\right] \mathrm{Cl}$, resulting in low glucose yield $(<15 \%)$. Xylose yields are higher since xylan is easier to dissolve compared to glucan (Sun et al., 2013). Based on these observations, dissolution or swelling of the cell wall seems essential for the following hydrolysis step. With increasing pretreatment temperature, the glucose yields after acidolysis increased dramatically 
(13.5\% to $69.6 \%$ for CS, $32.5 \%$ to $60.5 \%$ for CS: MSW=3:1, 37.3\% to $73.5 \%$ for

CS:MSW=1:1, and $12.5 \%$ to $74.7 \%$ for MSW). The sugar yields generally increase as a function of incubation time, with a maximum observed at 150 minutes. The increases in sugar yields are more significant after pretreatment at lower temperatures (i.e. $6.7 \%$ to $13.5 \%$ for CS pretreated at $120^{\circ} \mathrm{C}$ vs. $67.5 \%$ to $69.6 \%$ for CS pretreated at $160{ }^{\circ} \mathrm{C}$ ). For pretreated CS/MSW blends (3:1), the sugar yields were maximized after incubation for 90 (pretreated @ $160^{\circ} \mathrm{C}$ ) or 120 (pretreated @ $140{ }^{\circ} \mathrm{C}$ ) minutes. The highest glucose $(80.6 \%)$ and xylose $(90.8 \%)$ yields are obtained after pretreatment of MSW at $140{ }^{\circ} \mathrm{C}$ for $2 \mathrm{~h}$. For the MSW/CS blends, the yields are observed to decrease overall, with highest sugar production of $79.4 \%$ for glucose and $64.1 \%$ for xylose with equal mass blending of MSW and CS and pretreated at $140{ }^{\circ} \mathrm{C}$ for $2 \mathrm{~h}$. With more CS blended in (CS:MSW = 3:1) the sugar yields further decreases, and the optimal conditions obtained with pretreatment at $160^{\circ} \mathrm{C}$ for $2 \mathrm{~h}$ and acidolysis for 90 minutes. Thus, with more CS blending into the feedstock, higher temperature pretreatment is preferred for glucose production while xylose yields dropped, possibly due to the degradation of xylose. Overall both MSW and MSW/CS blends can be efficiently converted to sugars through either chemical pathway (acidolysis) or biological pathway (enzymatic sacchrification). Both of the two approaches involve biomass pretreatment for the first step to overcome the biomass recalcitrance. The pretreatment efficiency is highly dependent on the pretreatment conditions such as temperature and time. Under the optimized conditions, the sugar yields of MSW for enzymatic hydrolysis is $81.9 \%$ for glucose and $75.2 \%$ for xylose; while $80.6 \%$ glucose and 90.8\% xylose yields are obtained for acidolysis. Thus, these two approaches have similar performance for sugar production from MSW and MSW/CS blends with acidolysis process superior in terms of xylose relase.

Rheology. The rheological properties of pretreated MSW, CS, and MSW/CS blends from two IL pretreatment processes were assessed to gain further insight into the deconstruction process. Figure 5 shows the viscosity profiles of the biomass materials after $\left[\mathrm{C}_{2} \mathrm{C}_{1} \mathrm{Im}\right] \mathrm{Cl}$ pretreatment (PT, Figure 5a) as well as $\left[\mathrm{C}_{2} \mathrm{C}_{1} \mathrm{Im}\right] \mathrm{Cl}$ pretreatment and acidolysis (PT+AD, Figure $\left.5 \mathrm{~b}\right)$. The viscosities of the solids after $\left[\mathrm{C}_{2} \mathrm{C}_{1} \mathrm{Im}\right][\mathrm{OAc}]$ pretreatment and washing with water $(\mathrm{PT}+\mathrm{WS})$ are shown in Figure 3S.

Upon $\left[\mathrm{C}_{2} \mathrm{C}_{1} \mathrm{Im}\right] \mathrm{OAc}$ pretreatment and washing (PT+WS), MSW showed highest viscosity 
compared to MSW/CS blends (1:1) and CS. Decrease of MSW reduces the viscosity by $62 \%$ (42.0 vs 16.1 Pa.s at $100 \mathrm{~s}^{-1}$ ). Solids recovered from all samples of PT and PT+WS treatments behaved visco-elastic with a dominant elastic component ( 10 degree Phase Angle). The solid-like behavior from biomass probably emanated from the polymeric form of cellulose after PT and PT+WS.

After $\left[\mathrm{C}_{2} \mathrm{C}_{1} \mathrm{Im}\right] \mathrm{Cl}$ pretreatment, MSW (PT) showed higher viscosity levels than CS (PT) but both MSW/CS blends at 1:1 and 1:3 ratios (PT) showed similar and somewhat of an intermediate viscosity profile between those of MSW and CS. Although corn stover itself was not easily pretreated and saccharified, addition of corn stover in MSW helped lowering viscosity of the reaction mixture in the pretreatment stage, allowing better mass transfer between acid and dissolved cellulose, thus results in better hydrolysis of the convertible fraction as evidenced in high glucose release from 3:1 or 1:1 blending ratios after pretreatment at $120{ }^{\circ} \mathrm{C}$ for the MSW/CS blends (32.5\% for the blend CS:MSW=3:1 and 37.3\% for the blend CS:MSW=1:1 vs. $13.5 \%$ for CS and $12.5 \%$ for MSW). As expected, acidolysis step converts polymeric cellulose/hemicellulose to monomeric glucose/xylose and accordingly changes the rheological behavior as well. The viscosities of both CS and MSW dropped from 9.0 (CS, PT) and 78.5 (MSW, PT) to 0.51 (CS, PT+AD) and 0.30 Pa.s (MSW, PT+AD) at 100s ${ }^{-1}$. MSW after pretreatment and acidolysis has lower viscosity than CS, which can be correlated with their sugar conversions as MSW has the highest glucose and xylose release $(80.6 \%$ for glucose and $90.8 \%$ for xylose) compared to CS that has much lower conversion (29.2\% for glucose and $55.8 \%$ for xylose). At this stage, the samples are very liquid-like (90 degree phase angle) and were pumpable beyond $6 \mathrm{~Pa}$ stress (yield stress). The most interesting results came from the sample of MSW/CS blends (PT+AD), where 1:1 blend $(\mathrm{PT}+\mathrm{AD})$ had the similar viscosity with CS (PT+AD); however, 1:3 blend (PT+AD) had the lowest viscosity level of 0.15 Pa.s at 100 $\mathrm{s}^{-1}$. It is unclear why the blends' viscosity didn't follow the trend as their sugar releases, and merits further investigations. 


\section{Conclusions}

MSW can be blended into corn stover (CS) providing lower cost biorefinery feedstock inputs that are easily pretreated using the IL pretreatment technology. After pretreatment in $\left[\mathrm{C}_{2} \mathrm{C}_{1} \operatorname{Im}\right][\mathrm{OAc}]$, up to $84 \%$ glucose and $75 \%$ xylose are released. Pretreatment in $\left[\mathrm{C}_{2} \mathrm{C}_{1} \operatorname{Im}\right] \mathrm{Cl}$ followed by acidolysis is also efficient with maximums of $80 \%$ glucose yield and $90 \%$ xylose 334 yield. Although MSW gives the highest sugar yields, the viscosity of the slurry after 335 pretreatment was high. Blending CS with MSW helps to decrease the viscosity making the 336 mixture more transferable. The results suggest the great potential to use MSW for biofuel 337 production while maintaining performance and lowering costs.

\section{Acknowledgments}

340 The enzyme mixtures used in this study were obtained as a gift from Novozymes. This work 341 was supported by funding from the DOE Energy Efficiency and Renewable Energy's 342 BioEnergy Technology Office. The portion of the work conducted by the Joint BioEnergy 343 Institute was supported by the Office of Science, Office of Biological and Environmental 344 Research, of the U.S. Department of Energy under Contract No. DE-AC02-05CH11231. 


\section{References}

1. Binder, J., Raines, R. 2010. Fermentable sugars by chemical hydrolysis of biomass. PNAS, 107, 4516-4521.

2. Environmental Protection Agency Report, 2010. Renewable Fuel Standard Program - Regulatory Impact Analysis p53.

3. INL/EXT-13-30342. 2013. Feedstock Supply System Design and Economics for Conversion of Lignocellulosic Biomass to Hydrocarbon Fuels https://inlportal.inl.gov/portal/server.pt/gateway/PTARGS_0_6663_148104_0_0_18/Feedstock\%20Jou le_Biochem\%20Design_Draft_Final_v2\%20(4).pdf Last accessed 10/06/2014.

4. Klein-Marcuschamer, D., Oleskowicz-Popiel, P., Simmons, B.A., Blanch, H.W. 2010. Technoeconomic analysis of biofuels: A wiki-based platform for lignocellulosic biorefineries. Biomass Bioenergy, 34 , 1914-1921.

5. Li, C., Knierim, B., Manisseri, C., Arora, R., Scheller, H.V., Auer, M., Vogel, K.P., Simmons, B.A., Singh, S. 2010. Comparison of dilute acid and ionic liquid pretreatment of switchgrass: Biomass recalcitrance, delignification and enzymatic saccharification. Bioresour. Technol., 101, 4900-6.

6. Sluiter, A. 2004. Determination of structural carbohydrates and lignin in biomass. National Renewable Energy Laboratory (NREL) Analytical Procedures.

7. Socha, A.M., Parthasarathi, R., Shi, J., Pattathil, S., Whyte, D., Bergeron, M., George, A., Tran, K., Stavila, V., Venkatachalam, S. 2014. Efficient biomes pretreatment using ionic liquids derived from lignin and chemically. PNAS, 111, E3587-E3595.

8. Sun, N., Liu, H., Sathitsuksanoh, N., Stavila, V., Sawant, M., Bonito, A., Tran, K., George, A., Sale, K.L., Singh, S. 2013. Production and extraction of sugars from switchgrass hydrolyzed in ionic liquids. Biotechnol. Biofuels, 6, 1-15.

9. Sun, N., Parthasarathi, R., Socha, A.M., Shi, J., Zhang, S., Stavila, V., Sale, K.L., Simmons, B.A., Singh, S. 2014. Understanding pretreatment efficacy of four cholinium and imidazolium ionic liquids by chemistry and computation. Green Chem., 16, 2546-2557.

10. The Biomass Research and Development Board Report, 2008. Increasing Feedstock Production for Biofuels: Economic Drivers, Environmental Implications, and the Role of Research. http://www.esd.ornl.gov/eess/8_Increasing_Biofuels_Feedstock_Production.pdf. Last accessed 2/12/15.

11. Thompson, V.S.R., Allison E.; Sun, Ning; Singh, Seema; Simmons, Blake A. 2014. Assessment of municipal solid waste as a blend feedstock to lower biomass feedstock costs. 36th Symposium on Biotechnology for Fuels and Chemicals. April 28-May 1, 2014, Clearwater Beach, FL.

12. U.S. Department of Energy. 2011. U.S. Billion-Ton Update: Biomass Supply for a Bioenergy and Bioproducts Industry. R.D. Perlack and B.J. Stokes (Leads), ORNL/TM-2011/224. Oak Ridge National Laboratory, Oak Ridge, TN. 227p.

13. Williams, R.B. 2007. Biofuels from Municipal Wastes- Background Discussion Paper http://energy.ucdavis.edu/files/05-13-2013-2007-cbc-biofuels-from-municipal-solid-waste-background -paper.pdf Last accessed 2/12/15.

14. Xu, F., Shi, Y.-C., Wang, D. 2012. Enhanced production of glucose and xylose with partial dissolution of corn stover in ionic liquid, 1-Ethyl-3-methylimidazolium acetate. Bioresour.Technol., 114, 720-724. 
390 Table 1. Chemical composition ${ }^{\text {a }}$ before and after IL pretreatment

Feedstock

Glucan, $\% \quad$ Xylan, $\% \quad$ Lignin $^{\mathrm{c}}, \% \quad$ Ash, $\%$

\begin{tabular}{|c|c|c|c|c|c|}
\hline \multirow{2}{*}{ Corn stover } & raw & $33.2 \pm 1.0$ & $20.8 \pm 0.04$ & $18.7 \pm 1.5$ & $3.0 \pm 0.3$ \\
\hline & pretreated & $40.7 \pm 4.0$ & $26.2 \pm 2.2$ & $5.7 \pm 0.8$ & $9.6 \pm 0.5$ \\
\hline \multirow{2}{*}{$\begin{array}{l}\text { MSW } \\
\operatorname{mix}\end{array}$} & raw & $55.8 \pm 5.0$ & $10.0 \pm 1.4$ & $11.9 \pm 0.3$ & $10.9 \pm 1.3$ \\
\hline & pretreated & $52.6 \pm 7.2$ & $11.0 \pm 1.1$ & $12.0 \pm 1.7$ & $6.8 \pm 0.3$ \\
\hline \multirow{2}{*}{$\begin{array}{l}\text { CS/MSW } \\
(1: 1)\end{array}$} & raw & $46.0 \pm 3.1$ & $17.3 \pm 1.0$ & $16.0 \pm 0.6$ & $7.5 \pm 0.5$ \\
\hline & pretreated & $55.8 \pm 6.4$ & $16.3 \pm 0.4$ & $8.6 \pm 1.2$ & $7.6 \pm 0.6$ \\
\hline
\end{tabular}

${ }^{a}$ Values represent the average and standard deviation of each component on the basis of dry materials.

${ }^{\mathrm{b}}$ Klason (acid insoluble) lignin based on NREL LAPs.

396 Table 2. Ash and sugar compositions of CS/MSW blends

\begin{tabular}{ccccc}
\hline CS/MSW & Ash $(\%)$ & Glucan $(\%)$ & Xylan $(\%)$ & Glucan+Xylan $(\%)$ \\
\hline $90: 10$ & 3.8 & 35.5 & 19.7 & 55.2 \\
$80: 20$ & 4.6 & 37.7 & 18.6 & 56.3 \\
$70: 30$ & 5.4 & 40.0 & 17.6 & 57.6 \\
$60: 40$ & 6.2 & 42.2 & 16.5 & 58.7 \\
$50: 50$ & 7.0 & 44.5 & 15.4 & 59.9 \\
\hline
\end{tabular}

$397 *$ numbers in this table are the theoretical calculation based on the compositions of corn stover 398 and MSW paper mix 


\section{Figure legends}

Figure 1. Delivered feedstock costs for a) corn stover, b) $80 \%$ CS and 20\% MSW blend and c) $50 \% \mathrm{CS}$ and $50 \% \mathrm{MSW}$ blend

Figure 2. Mass balance of the pretreatment process followed by enzymatic hydrolysis.

Figure 3. Glucose (a) and xylose (b) yields before and after IL pretreatment and enzymatic saccharification.

409 Figure 4. Glucose and xylose yields after pretreatment and acidolysis of corn stover (CS), municipal solid 410 waste (MSW), and their blends with different ratios (1:1 and 1:3).

412 Figure 5. Viscosity profiles of municipal solid waste (MSW), corn stover (CS), and their 413 blends from the $\left[\mathrm{C}_{2} \mathrm{C}_{1} \mathrm{Im}\right] \mathrm{Cl}$ process, PT: after pretreatment at $140{ }^{\circ} \mathrm{C}$, and $\mathrm{PT}+\mathrm{AD}$ : after 414 pretreatment at $140{ }^{\circ} \mathrm{C}$ followed by acidolysis at $105^{\circ} \mathrm{C}$. 
a)

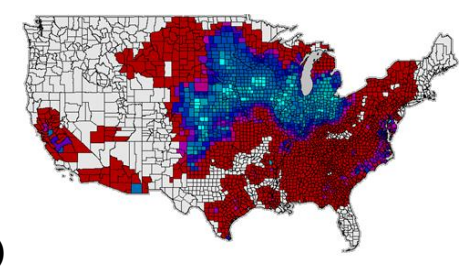

b)

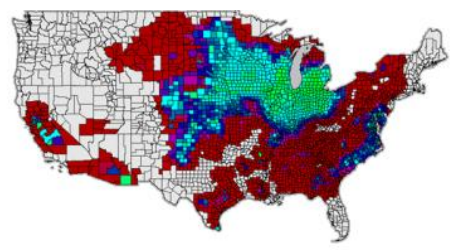

c)

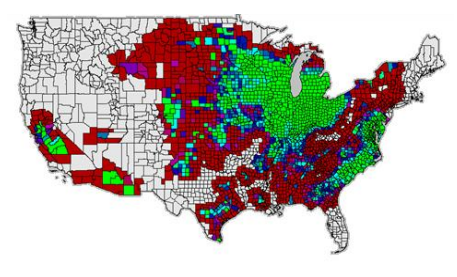

417 Figure 1. Delivered feedstock costs for a) corn stover, b) $80 \%$ CS and 20\% MSW blend and c)

$418 \quad 50 \% \mathrm{CS}$ and 50\% MSW blend 


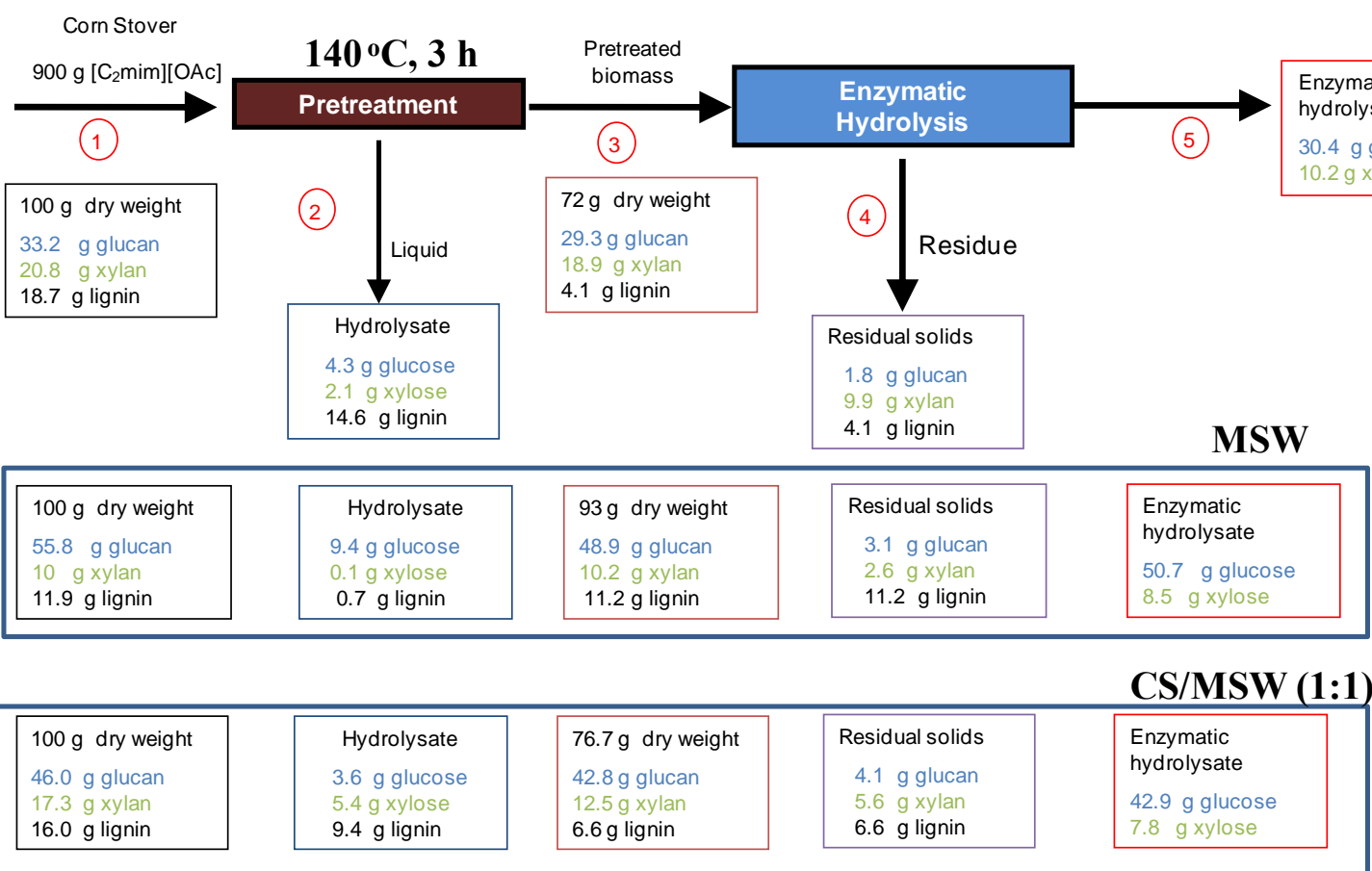

Figure 2. Mass balance of the pretreatment process followed by enzymatic hydrolysis. 

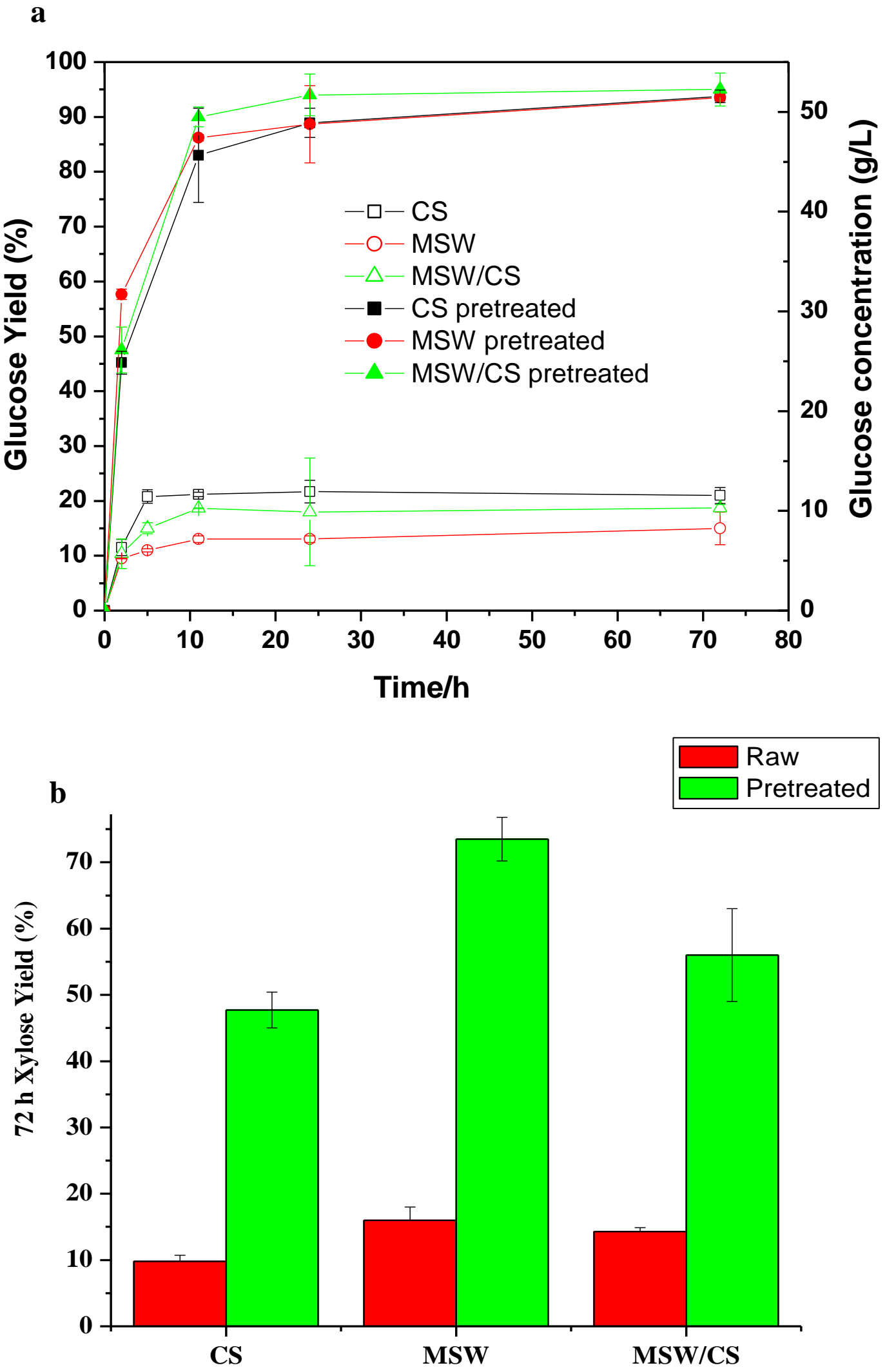

425 Figure 3. Glucose (a) and xylose (b) yields before and after IL pretreatment and enzymatic 426 saccharification. 

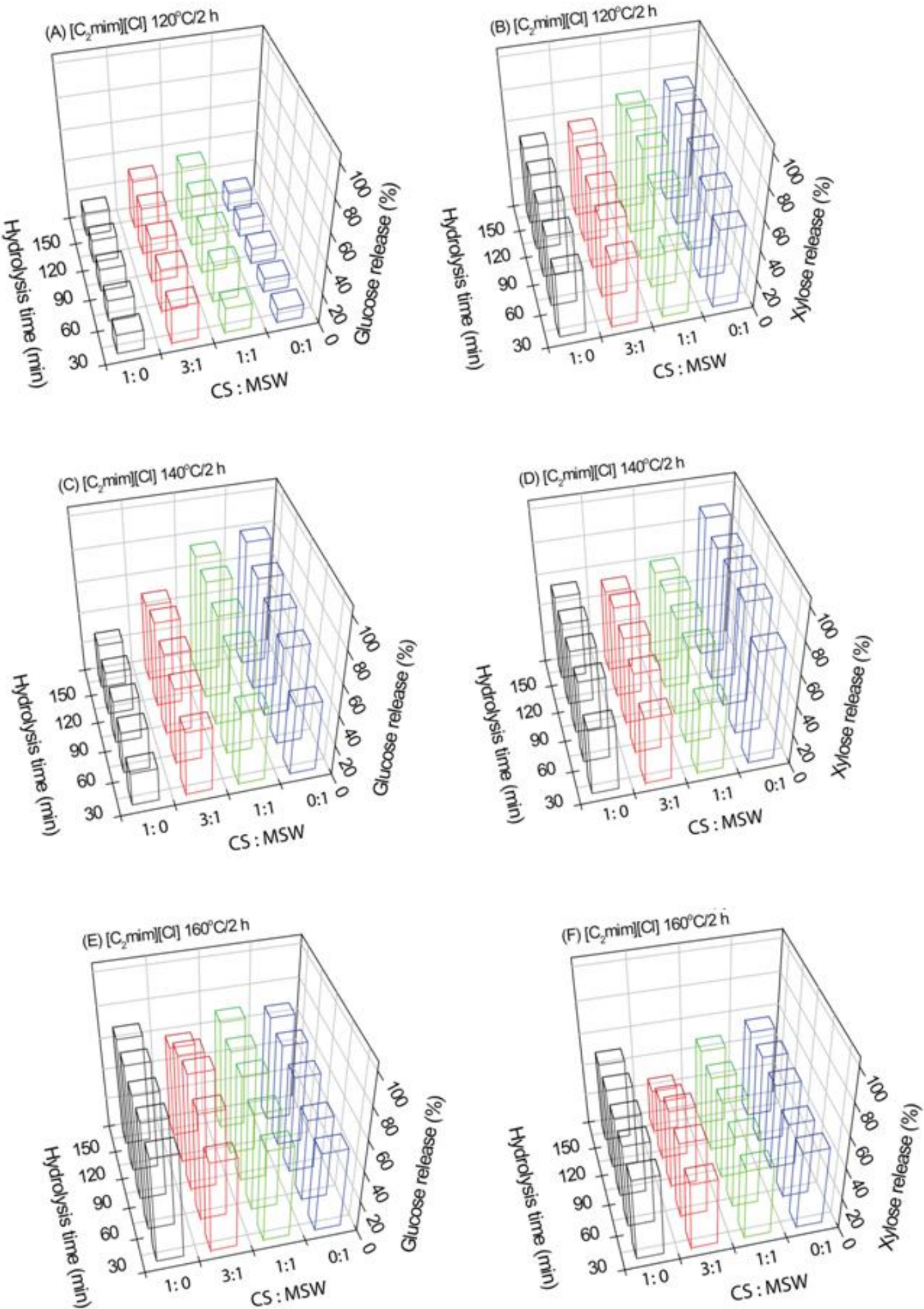

Figure 4. Glucose and xylose yields after pretreatment and acidolysis of corn stover (CS), municipal solid 430 waste (MSW), and their blends with different ratios (1:1 and 1:3). 

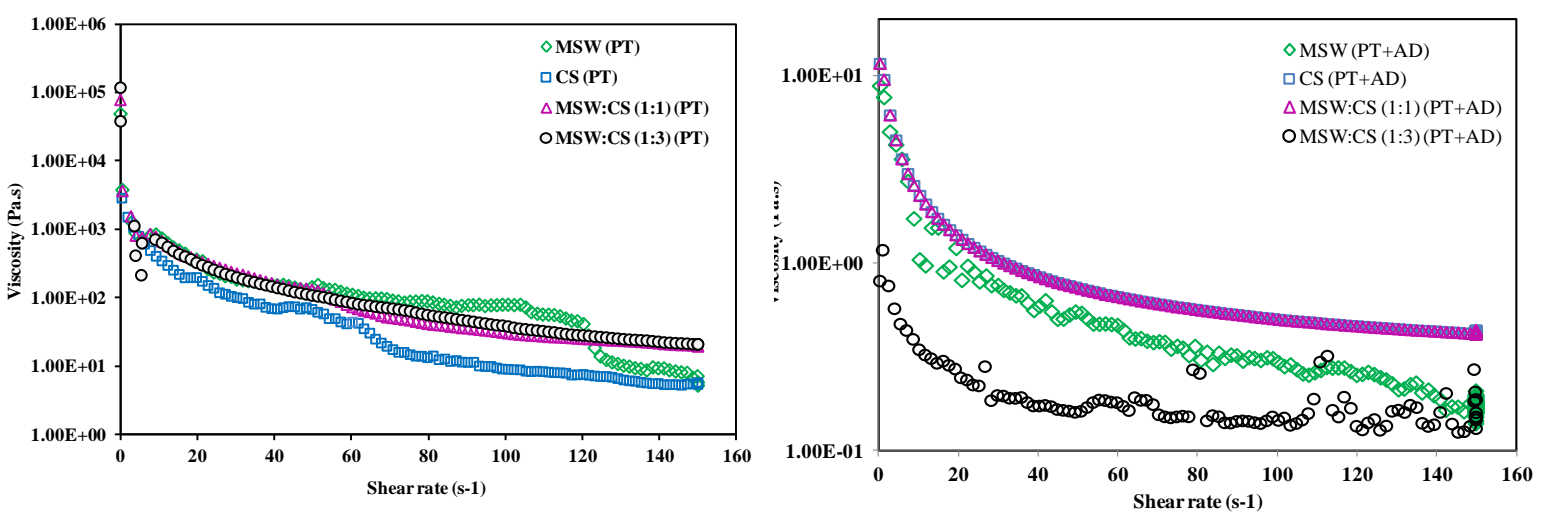

432 Figure 5. Viscosity profiles of municipal solid waste (MSW), corn stover (CS), and their 433 blends from the $\left[\mathrm{C}_{2} \mathrm{C}_{1} \mathrm{Im}\right] \mathrm{Cl}$ process, PT: after pretreatment at $140{ }^{\circ} \mathrm{C}$, and $\mathrm{PT}+\mathrm{AD}$ : after 434 pretreatment at $140{ }^{\circ} \mathrm{C}$ followed by acidolysis at $105^{\circ} \mathrm{C}$. 